Supporting Information

for

\title{
Immobilized chiral ortho-metalated dirhodium(II) compounds as catalysts in the asymmetric cyclopropanation of styrene with ethyl diazoacetate.
}

Julio Lloret, Francisc Estevan, Klaus Bieger, Cristina Villanueva and $M^{a}$ Angeles Úbeda*.

Departamento de Química Inorgánica, Facultad de Química, Universitat de Valencia, Dr.Moliner 50, 46100 Burjassot, Valencia, Spain. Fax: (34)963544322, E-mail: angeles.ubeda@uv.es. 

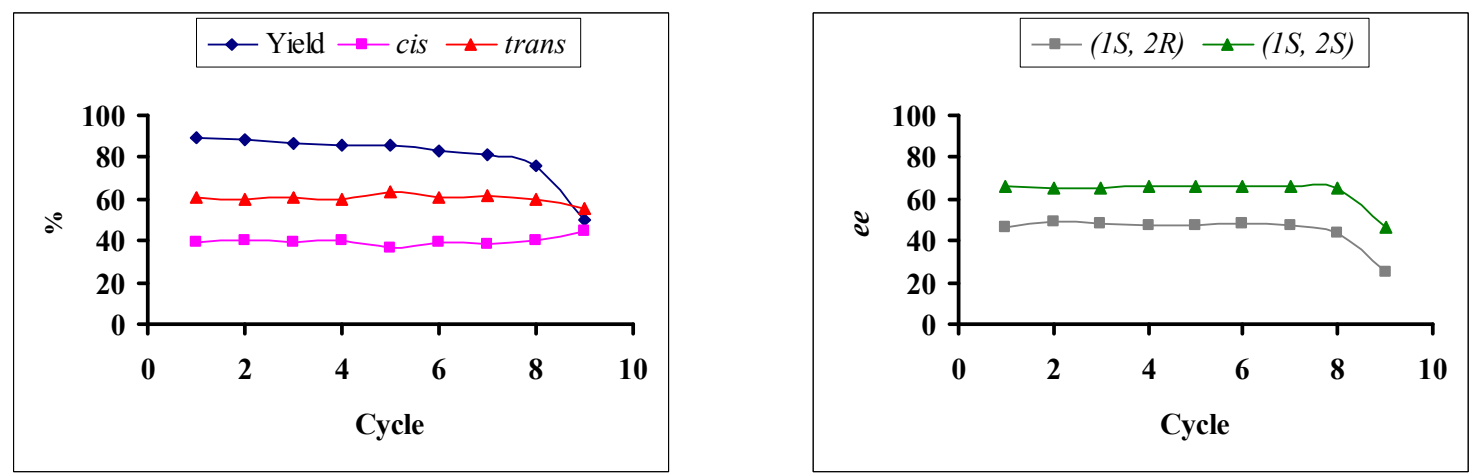

Figure SI.1. Variation of the yields, percentages and ee of the cis-and transcyclopropane isomers using recycled $\mathbf{1 6}, \mathrm{X}=\mathrm{CF}_{3}$, for 9 cycles.
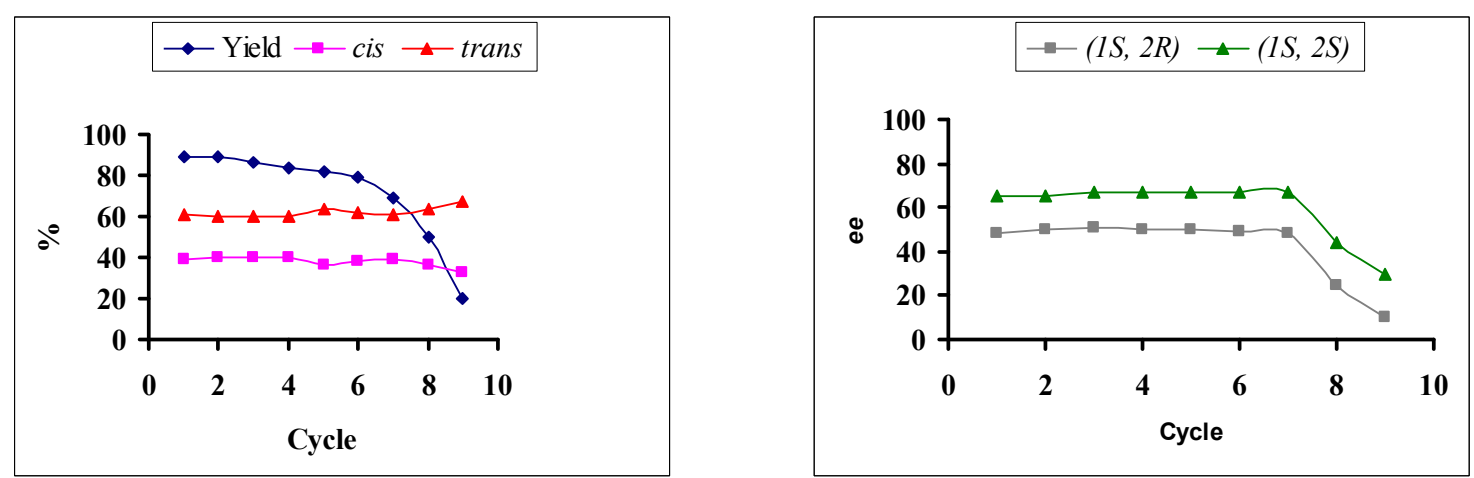

Figure SI.2. Variation of the yields, percentages and ee of the cis- and transcyclopropane isomers using recycled $\mathbf{1 3}, \mathrm{X}=\mathrm{F}$, for 9 cycles.
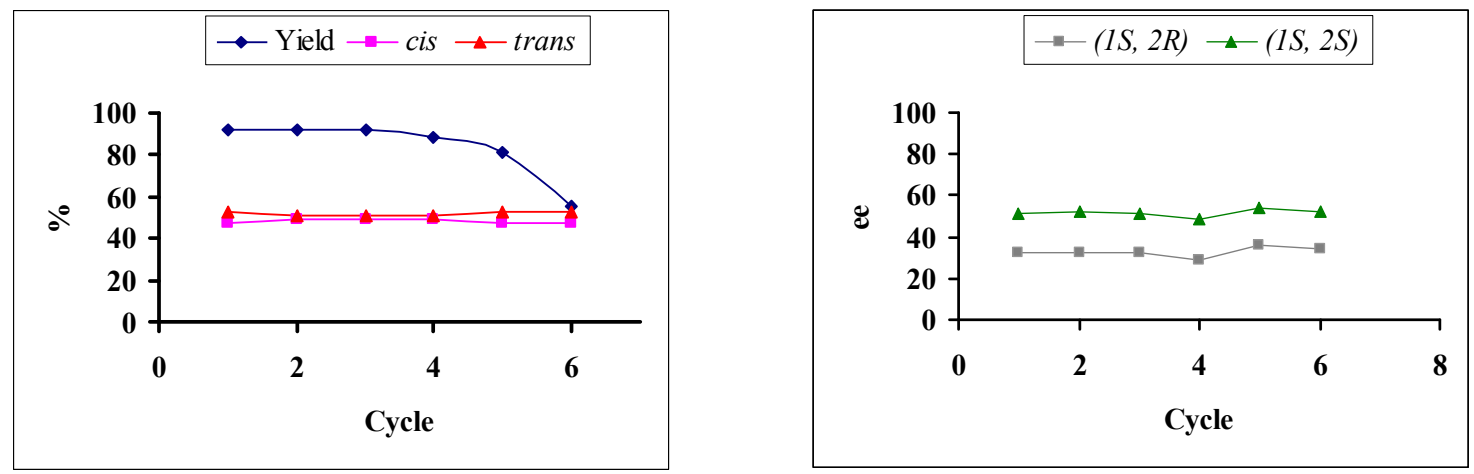

Figure S.I.3. Variation of the yields, percentages and ee of the cis- and transcyclopropane isomers using recycled $15, X=B r$, for 6 cycles. 

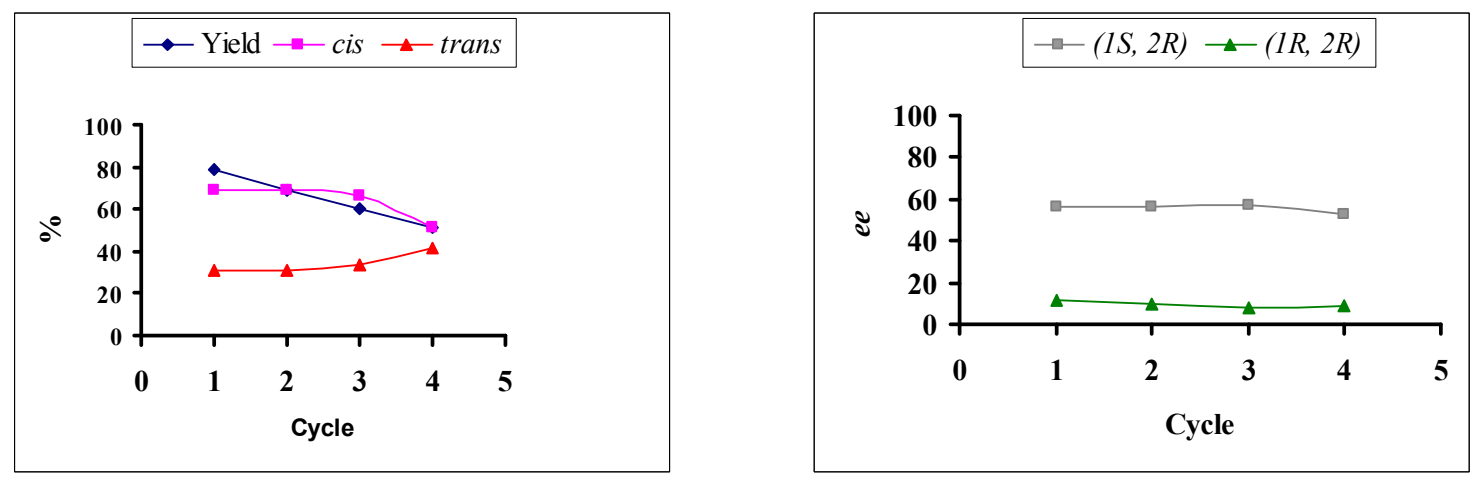

Figure SI.4. Variation of the yields, percentages and ee of the cis- and transcyclopropane isomers using recycled $19, \mathrm{X}=\mathrm{SiMe}_{3}$, for 4 cycles. 
